\title{
Determination of ppb Level of Arsenic(V) Based on Fluorescence Quenching of Thorium-Morin Chelate
}

\author{
Yuzo Tamari, Akihiro Takada, Haruo Tsuj and Yuzuru Kusaka \\ Department of Chemistry, Faculty of Science, Konan University, Okamoto, Higashinada, Kobe 658
}

\begin{abstract}
Morin $\left(5,7,2^{\prime}, 4^{\prime}\right.$-tetrahydroxyflavonol) forms a stable chelate with thorium(IV). The chelate showed a constant fluorescence intensity $\left(\lambda_{\mathrm{ex}} 415 \mathrm{~nm}, \lambda_{\mathrm{em}} 505 \mathrm{~nm}\right)$ in acidic solutions, $\mathrm{pH}$ 2.2. The stoichiometric composition of the chelate was 1:1 (thorium:morin). In the presence of arsenic(V), the chelate dissociated, owing to the formation of a more stable complex of thorium arsenate. By using the experimental result that the fluorescence intensity of thorium-morin chelate decreased in proportion to the concentration of arsenic(V), $0.01-1 \mathrm{ppm}$ of arsenic(V) could be determined. In the reaction, arsenic(III) did not form a thorium arsenite complex. Accordingly, arsenic(V) in the mixture of arsenic(III) and arsenic( $M$ was accurately determined by the fluorescence quenching method.
\end{abstract}

Keywords Arsenic determination, spectrofluorometry, fluorescence quenching, thorium-morin chelate

Morin (5,7,2', $4^{\prime}$-tetrahydroxyflavonol) has been used as the reagent for spectrophotometry and for spectrofluorometry of many metal ions. ${ }^{1}$ Morin forms a stable fluorescent chelate with thorium(IV) in acidic solution. Sulfate ion forms more stable complex with thorium(IV) than its morin chelate. ${ }^{1,2}$ Since the fluorescence intensity of the thorium-morin chelate was inversely proportional to the concentration of the sulfate ion, the determination of sulfate has been achieved. ${ }^{2,3}$

We have found that the presence of arsenic(V) also quenched the fluorescence of the thorium-morin chelate by the dissociation of the chelate and then by the formation of a new complex of thorium arsenate at $\mathrm{pH}$ 2.2. In this acidic medium, the free morin dissociated was not very fluorescent, compared with the thoriummorin chelate. Accordingly, the fluorescence intensity of the chelate decreased in proportion to the concentration of arsenic(V). By using this exchangeable reaction of thorium(IV), the ppb level of arsenic(V) was determined. Since arsenic(III) could not form thorium-arsenite complex, arsenic(V) in the solution containing arsenic(III) could be selectively determined by this fluorometry.

\section{Experimental}

\section{Reagents}

Highly pure water, obtained by distilling twice doubly de-ionized water, was used throughout the present study.

A standard $1000 \mathrm{mg} / 1$ stock solution of arsenic(III) was prepared by dissolving $0.1320 \mathrm{~g}$ of arsenic(III) trioxide $(99.5 \%$ ), obtained from Nakarai Chemicals Ltd., Kyoto, with $10 \mathrm{ml}$ of $1 \mathrm{M}$ sodium hydroxide, and by making up to $100 \mathrm{ml}$ with water after addition of $6 \mathrm{ml}$ of $2 \mathrm{M}$ hydrochloric acid.

A standard $100 \mathrm{mg} / 1$ stock solution of $\operatorname{arsenic}(\mathrm{V})$ was prepared as follows: Add $5 \mathrm{ml}$ of concentrated nitric acid and $1 \mathrm{ml}$ of $6 \mathrm{M}$ hydrochloric acid to $10 \mathrm{ml}$ of the standard arsenic(III) stock solution. Dry up the solution in a beaker on a boiling water-bath. Dissolve the evaporated residue with water, and make it up to $100 \mathrm{ml}$ with water.

Thorium(IV) $1000 \mathrm{mg} / \mathrm{l}$ stock solution was prepared by dissolving $0.2379 \mathrm{~g}$ of thorium(IV) nitrate tetrahydrate (Wako Pure Chemical Industries Ltd., Osaka) with water, and by diluting it to $100 \mathrm{ml}$ with water.

Morin $500 \mathrm{mg} / 1$ stock solution was prepared by dissolving $0.05 \mathrm{~g}$ of morin (Wako Chemical Industries Ltd.) with ethanol $(99.5 \mathrm{v} / \mathrm{v} \%)$ and by making up to $100 \mathrm{ml}$ with ethanol.

Working solutions of arsenic(III), arsenic(V), thorium(IV), and morin were prepared by diluting each stock solution to be $1 \mathrm{mg} / \mathrm{l}, 1 \mathrm{mg} / 1$ (or $10 \mathrm{mg} / \mathrm{l}$ ), $10 \mathrm{mg} / \mathrm{l}$, and $50 \mathrm{mg} / \mathrm{l}$, respectively.

All other regents and solutions were of the highest purity available, and were used without further purification.

\section{Apparatus}

A spectrofluorometer (Model 650-10S; $150 \mathrm{~W}$ xenon lamp) and a pH meter equipped with a glass electrode (Model M-7), both from Hitachi Ltd., Tokyo, Japan, were used. 


\section{Analytical procedure}

To a centrifugal tube (Vol. $50 \mathrm{ml}$ ) with a cap, add $1 \mathrm{ml}$ of a solution containing $0.01-0.1 \mu \mathrm{g}$ of arsenic, $0.5 \mathrm{ml}$ of thorium(IV) solution (10 mg/l), $0.1 \mathrm{ml}$ of morin solution $(50 \mathrm{mg} / \mathrm{l})$ using a micro-pipet, and $16 \mathrm{ml}$ of ethanol. Make up them to $25 \mathrm{ml}$ with water after adjusting the $\mathrm{pH}$ to 2.2 with $0.5 \mathrm{M}$ hydrochloric acid. Shake the tube covered with its cap for about $10 \mathrm{~s}$, and warm the tube in a water-bath controlled thermostically to $30^{\circ} \mathrm{C}$ for $10 \mathrm{~min}$. Without cooling the tube, immediately measure the fluorescence intensity of the solution with the excitation and emission wavelengths of $415 \mathrm{~nm}$ and $505 \mathrm{~nm}$, respectively. Determine the concentrations of arsenic(V) in sample solutions by the calibration curve, in which the fluorescence intensity of a standard subtracted from that of a blank is plotted.

For the determination of the higher concentration of $\operatorname{arsenic}(V)(0.1-1 \mathrm{ppm})$, carry out the experiment in the same procedure as described above, after changing the volume to $3 \mathrm{ml}$ for the thorium $(10 \mathrm{mg} / 1)$ solution and to $0.3 \mathrm{ml}$ of the morin $(50 \mathrm{mg} / \mathrm{l})$ solution.

\section{Results and Discussion}

\section{Exitation and fluorescence spectra of thorium-morin chelate}

Figure 1 shows excitation and fluorescence spectra of thorium-morin chelate. In the presence of arsenic(V), the fluorescence intensity of the chelate decreased. In the absence of both thorium(IV) and arsenic(V), the fluorescence intensity of morin was much lower.

\section{Composition of thorium-morin chelate}

The stoicheiometric composition of thorium-morin chelate was determined to be $1: 1$ by Job's continuous

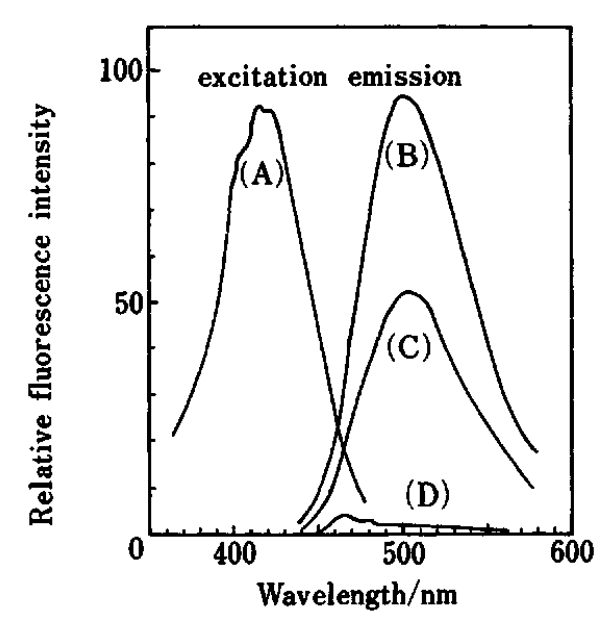

Fig. 1 Excitation and emission spectra of thorium-morin complex. (A), (B), $5 \mu \mathrm{g}$ each of Th(IV) and morin; (C), $5 \mu \mathrm{g}$ each of Th(IV) and morin in the presence of $0.5 \mu \mathrm{g}$ of As(V); (D), $5 \mu \mathrm{g}$ of morin; total volume, $25 \mathrm{ml}$. variation method and the molar-ratio method, as shown in Fig. 2. Thorium(IV), thus appears to bind to the carbonyl group and the hydroxyl group of morin, as in the case of flavonol. ${ }^{1}$

\section{Effect of various factors}

The maximum fluorescence intensity of thoriummorin chelate was observed when the $\mathbf{p H}$ of the chelate solution was 2.2, as shown in Fig. 3. In the presence of $\operatorname{arsenic}(V)$, the maximum fluorescence intensity was also observed at the same $2.2 \mathrm{pH}$ (Fig. 3).

Figure 4 shows that the maximum and constant fluorescence intensity of the chelate was found when more than $15 \mathrm{ml}$ of ethanol was added for the $25 \mathrm{ml}$ of the total volume, i.e., $60 \%(\mathrm{v} / \mathrm{v})$ ethanol. The increase in fluorescence intensity of the chelate with ethanol is probably due to the effect of solvent. ${ }^{4}$ As another reason, this increase may be due to the formation of more thorium-arsenate complexes rather than forma-
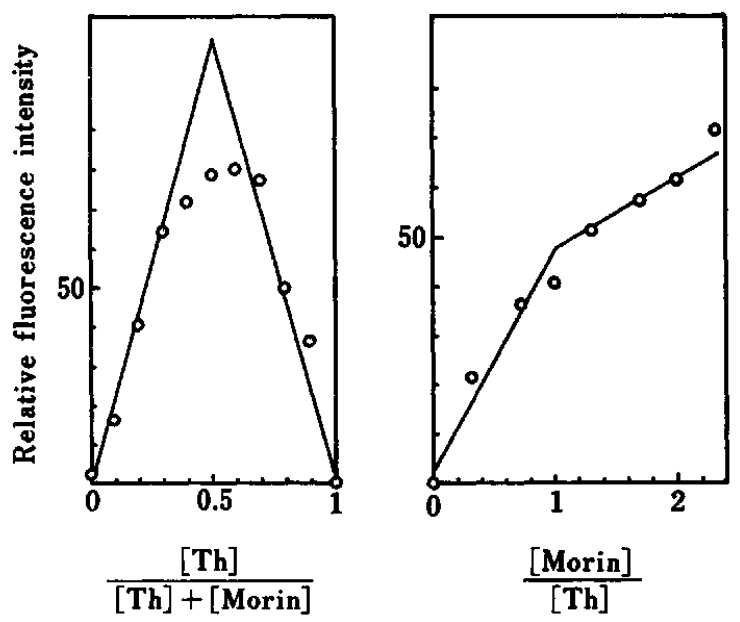

Fig. 2 Composition of thorium-morin complex by Job's continuous variation method and the molar-ratio method.

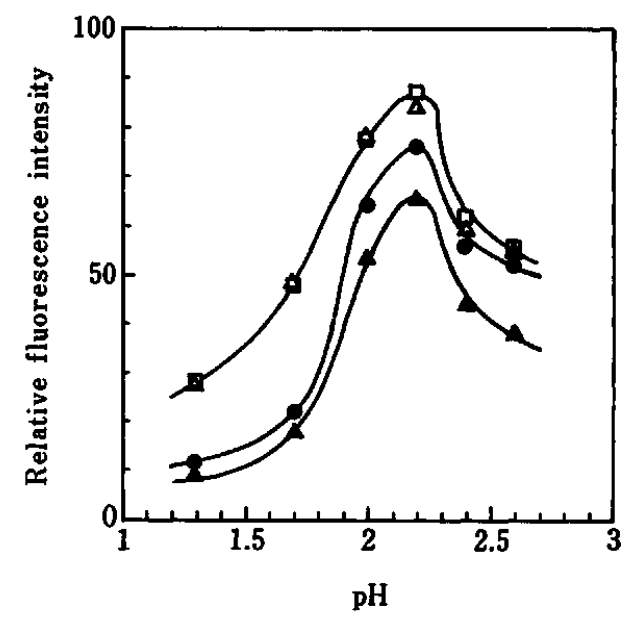

Fig. 3 Effect of $\mathrm{pH}$ on the formation of thorium-morin complex. $\square$ blank ( $5 \mu \mathrm{g}$ each of Th and morin); $\Delta$ blank ( $30 \mu \mathrm{g}$ of $\mathrm{Th}$ and $15 \mu \mathrm{g}$ of morin); sample ( $5 \mu \mathrm{g}$ each of Th and morin with $1 \mu \mathrm{g}$ of As(V)); $\Delta$ sample $(30 \mu \mathrm{g}$ of $\mathrm{Th}$ and $15 \mu \mathrm{g}$ of morin with $10 \mu \mathrm{g}$ of $\mathrm{As}(\mathrm{V}))$; total volume, $25 \mathrm{ml}$. 
tion of the olation of thorium hydroxide.

Figure 5 shows calibration curves. A straight line was obtained, when morin $5 \mu \mathrm{g}$ and thorium $5 \mu \mathrm{g}$, or morin $5 \mu \mathrm{g}$ and thorium $30 \mu \mathrm{g}$ were used for the determination of the lower concentration of arsenic(V) $(0.01-0.1 \mathrm{ppm})$ or the higher one $(0.1-1 \mathrm{ppm})$.

In Fig. 6, a linear calibration curve was found when $5 \mu \mathrm{g}$ of morin, in the presence of $5 \mu \mathrm{g}$ or $30 \mu \mathrm{g}$ of thorium, was used for the determination of the lower and higher concentration of arsenic. Accordingly, we decided to use those amounts for this fluorometry.

As can be seen in Fig. 7, the replacement reaction of a thorium-morin complex by a thorium-arsenate one depended on the reaction temperature. Linear calibration curves were obtained only at $30^{\circ} \mathrm{C}$, though the higher fluorescence intensity was obtained at $5^{\circ} \mathrm{C}$

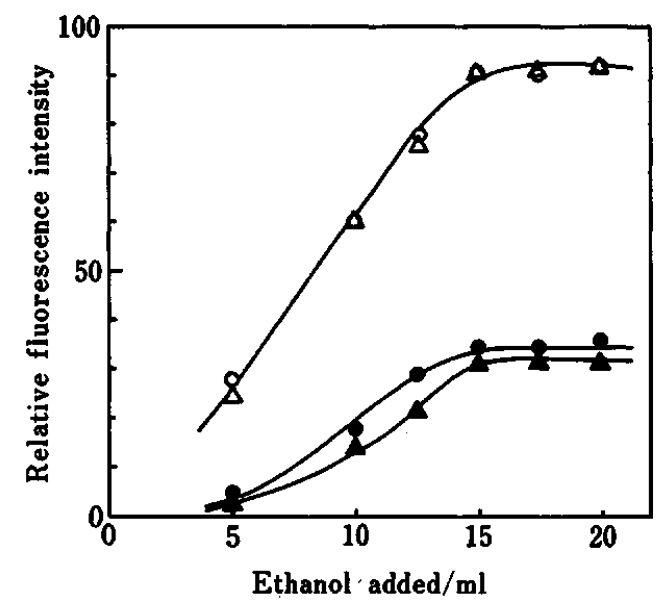

Fig. 4 Effect of the concentration of ethanol. O blank (each $5 \mu \mathrm{g}$ of Th and morin); $\Delta$ blank (30 $\mathrm{g}$ of Th, $15 \mu \mathrm{g}$ of morin); - sample (5 $\mu \mathrm{g}$ each of $\mathrm{Th}$ and morin with $0.5 \mu \mathrm{g}$ of $\mathrm{As}(\mathrm{V}))$; $\Delta$ sample $(30 \mu \mathrm{g}$ of $\mathrm{Th}$ and $15 \mu \mathrm{g}$ of morin with $5 \mu \mathrm{g}$ of As(V)); total volume, $25 \mathrm{ml}$.

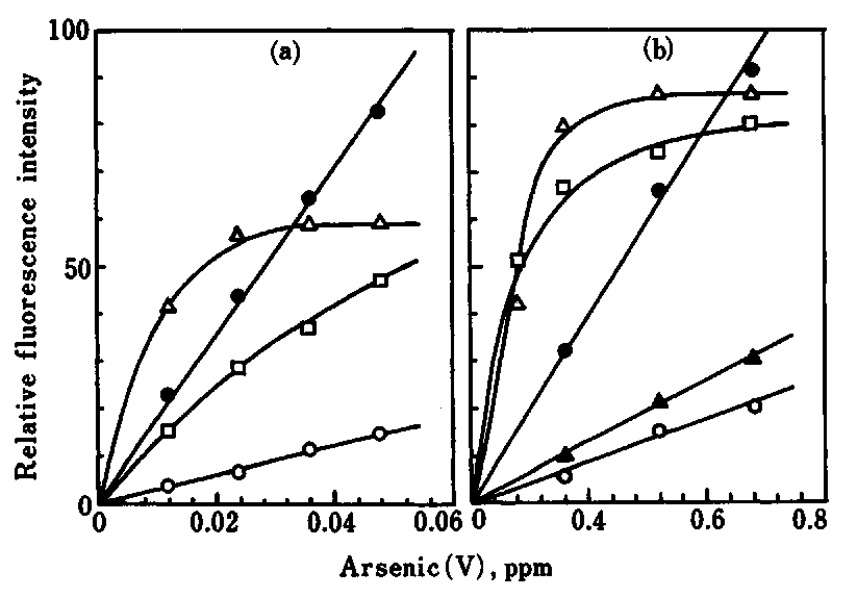

Fig. 5 Effect of the concentration of thorium. (a) Th: $\bigcirc 3 \mu \mathrm{g} ;-5 \mu \mathrm{g} ; \square 10 \mu \mathrm{g} ; \Delta 20 \mu \mathrm{g} ; 5 \mu \mathrm{g}$ of morin; total volume, $25 \mathrm{ml}$; (b) Th: $\bigcirc 3 \mu \mathrm{g}$; $\square 10 \mu \mathrm{g} ; \Delta 20 \mu \mathrm{g}$; $\bullet 3 \mu \mathrm{g}$; $\Delta 300 \mu \mathrm{g} ; 15 \mu \mathrm{g}$ of morin; total volume, $25 \mathrm{ml}$. or $10^{\circ} \mathrm{C}$. The time required for the replacement reaction was more than about $5 \mathrm{~min}$, as is depicted in Fig. 8. In this work, the reaction time was settled to be $10 \mathrm{~min}$ in the recommended procedure.

\section{Recovery of arsenic $(V)$ in the recommended procedure}

Table 1 shows the recovery percentages of arsenic(V) in the recommended procedure. Even in the presence of arsenic(III), arsenic(V) was recovered almost $100 \%$, and its relative standard deviation $(n=3)$ was about $1-3 \%$.

\section{Effect of coexisting ions}

In order to apply this quenching fluorometry to fresh waters, the dissolved chemical species such as $\mathrm{Na}^{+}, \mathrm{K}^{+}$, $\mathrm{Ca}^{2+}, \mathrm{Mg}^{2+}$ and $\mathrm{SO}_{4}{ }^{2-}$, and soluble $\mathrm{SiO}_{2}$, and reagents used for general pre-treatment such as $\mathrm{NH}_{4} \mathrm{OH}, \mathrm{HNO}_{3}$ and $\mathrm{HClO}_{4}$ were tested in the presence of $1 \mu \mathrm{g}$ of arsenic(V). Table 2 lists the results of this experiment. Since the $\mathrm{Ca}^{2+}, \mathrm{SO}_{4}{ }^{2-}$ and $\mathrm{SiO}_{2}$ ions which are dissolved mainly in fresh waters were considerably interfered

Table 1 Recovery of $\operatorname{arsenic}(V)$ in the recommended procedure

\begin{tabular}{|c|c|c|c|}
\hline $\begin{array}{c}\text { As(III) } \\
\text { added / } \\
\text { mg }\end{array}$ & $\begin{array}{c}\text { As(V) } \\
\text { added/ } \\
\text { mg }\end{array}$ & $\begin{array}{c}\text { As(V) } \\
\text { found/ } \\
\text { mg }\end{array}$ & $\begin{array}{l}\text { As(V) } \\
\text { recovery, } \\
\%\end{array}$ \\
\hline 0.5 & 0.5 & 0.483 & 96.6 \\
\hline 0.5 & 0.5 & 0.514 & 103 \\
\hline \multirow[t]{2}{*}{0.5} & 0.5 & 0.495 & 99.0 \\
\hline & & average & $99.5 \pm 3.2$ \\
\hline 1.0 & 1.0 & 1.01 & 101 \\
\hline 1.0 & 1.0 & 0.986 & 98.6 \\
\hline \multirow[t]{2}{*}{1.0} & 1.0 & 0.994 & 99.4 \\
\hline & & average & $99.6 \pm 1.2$ \\
\hline
\end{tabular}

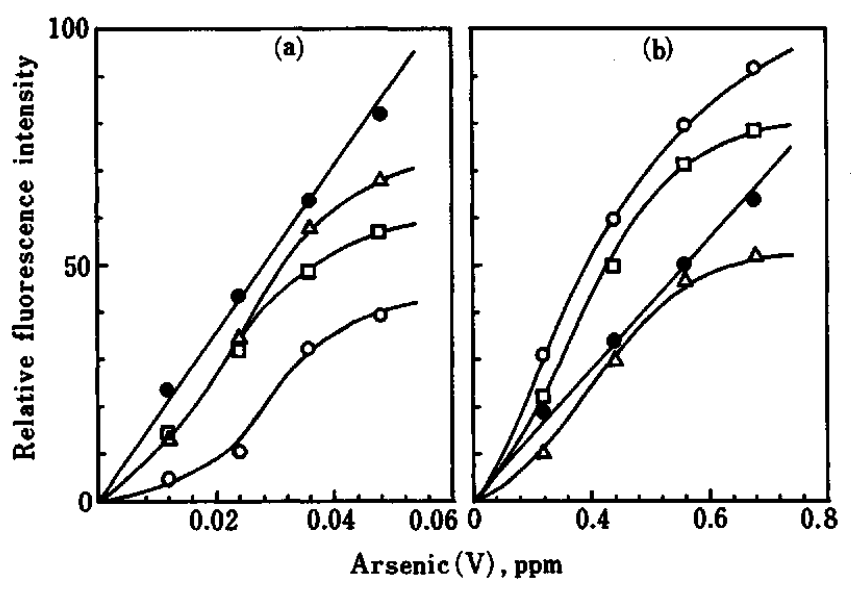

Fig. 6 Effect of the concentration of morin. (a) morin: $\Delta$ $2 \mu \mathrm{g} ;-5 \mu \mathrm{g} ; \square 15 \mu \mathrm{g} ; \bigcirc 45 \mu \mathrm{g} ; 5 \mu \mathrm{g}$ of $\mathrm{Th}$; total volume, $25 \mathrm{ml}$; (b) morin: $\bullet 5 \mu \mathrm{g} ; 015 \mu \mathrm{g} ; \square 50 \mu \mathrm{g} ; \Delta 150 \mu \mathrm{g} ; 30 \mu \mathrm{g}$ of Th; total volume, $25 \mathrm{ml}$. 
Table 2 Effect of coexisting ions

\begin{tabular}{|c|c|c|c|c|c|c|c|c|c|c|c|c|c|c|c|c|c|}
\hline \multicolumn{2}{|c|}{$\mathrm{Na}^{+}$} & \multicolumn{2}{|c|}{$\mathbf{K}^{+}$} & \multicolumn{2}{|c|}{$\mathrm{Ca}^{2+}$} & \multicolumn{2}{|c|}{$\mathrm{Mg}^{2+}$} & \multicolumn{2}{|c|}{$\mathrm{SiO}_{2}$} & \multicolumn{2}{|c|}{$\mathrm{NH}_{4}{ }^{+}$} & \multicolumn{2}{|c|}{$\mathrm{NO}_{3}^{-}$} & \multicolumn{2}{|c|}{$\mathrm{ClO}_{4}^{-}$} & \multicolumn{2}{|c|}{$\mathrm{SO}_{4}{ }^{2-}$} \\
\hline ppm & RFI & ppm & RFI & ppm & RFI & ppm & RFI & ppm & RFI & ppm & RFI & ppm & RFI & ppm & RFI & ppm & RFI \\
\hline 0 & 100 & 0 & 100 & 0 & 100 & 0 & 100 & 0 & 100 & 0 & 100 & 0 & 100 & 0 & 100 & 0 & 100 \\
\hline 1 & 108 & 0.1 & 100 & 1 & 142 & 0.2 & 97 & 1 & 46 & 0.4 & 109 & 1.3 & 99 & 1.3 & 47 & 2 & 12 \\
\hline 2 & 108 & 0.2 & 99 & 2 & 134 & 0.4 & 106 & 2 & 45 & 4 & 93 & 13 & 99 & 13 & 23 & 4 & 8 \\
\hline 4 & 110 & 0.4 & 98 & 4 & 123 & 1.0 & 96 & 5 & 30 & 40 & 92 & 130 & 96 & 130 & 9 & 10 & 9 \\
\hline 7 & 111 & 0.8 & 94 & 10 & 134 & 2.0 & 103 & 10 & 19 & 400 & 98 & 1300 & 76 & 1300 & 10 & 20 & 7 \\
\hline 20 & 117 & 2.0 & 93 & 20 & 160 & 4.0 & 95 & 20 & 9 & 4000 & 93 & 6500 & 49 & 13000 & 10 & 40 & 5 \\
\hline 30 & 118 & 4.0 & 93 & 40 & 156 & 8.0 & 102 & 50 & 3 & & & & & & & 100 & 7 \\
\hline 50 & 113 & 8.0 & 91 & 80 & 145 & 20.0 & 85 & 100 & 2 & & & & & & & 200 & 6 \\
\hline 70 & 113 & 12.0 & 85 & & & & & & & & & & & & & & \\
\hline
\end{tabular}

RFI (relative fluorescence intensity) was measured in the presence of $1 \mu \mathrm{g}$ of As(V), $5 \mu \mathrm{g}$ of $\mathrm{Th}(\mathrm{IV})$ and $5 \mu \mathrm{g}$ of morin. Total volume was $25 \mathrm{ml}$.

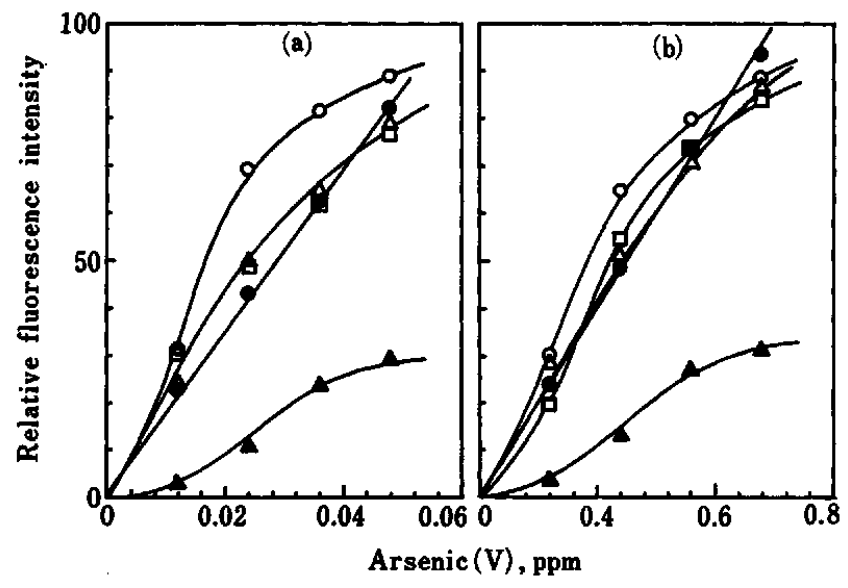

Fig. 7 Effect of reaction temperature. Temp.: $\bigcirc 5^{\circ} \mathrm{C} ; \Delta$ $10^{\circ} \mathrm{C}$; $20^{\circ} \mathrm{C}$; $30^{\circ} \mathrm{C}$; $\triangle 40^{\circ} \mathrm{C}$; total volume, $25 \mathrm{ml}$; reaction time, $10 \mathrm{~min}$; (a) $5 \mu \mathrm{g}$ each of Th(IV) and morin; (b) $30 \mu \mathrm{g}$ of $\mathrm{Th}(\mathrm{IV})$ and $5 \mu \mathrm{g}$ of morin.

with, this fluorometry was not applicable to the fresh water samples. However, the proposed fluorometry may be applied to the mixtures of arsenic(III) and arsenic(V) in the presence of $\mathrm{Na}^{+}, \mathrm{K}^{+}, \mathrm{Mg}^{2+}, \mathrm{NH}_{4}{ }^{+}$and $\mathrm{NO}_{3}{ }^{-}$, if they are contained within the limited amounts found in Table 2.

\section{References}

1. Y. Nishikawa and K. Hiraki, "Keikou Rünkou Bronsekihou”,

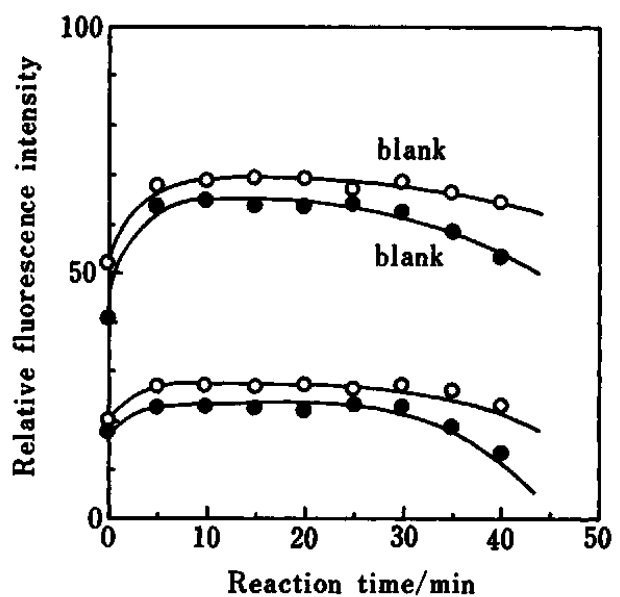

Fig. 8 Effect of reaction time. $0.5 \mu \mathrm{g}$ of $\mathrm{As}(\mathrm{V})(5 \mu \mathrm{g}$ each of Th and morin); $O 5 \mu \mathrm{g}$ of $\mathrm{As}(\mathrm{V})(30 \mu \mathrm{g}$ of Th and $15 \mu \mathrm{g}$ of morin); reaction temp., $30^{\circ} \mathrm{C}$; total volume, $25 \mathrm{ml}$.

p. 112, Kyouritsu Shuppan, Tokyo (1984).

2. T. Nasu, Bunseki Kagaku, 18, 1183 (1969).

3. T. Nasu, T. Kitagawa and T. Mori, Bunseki Kagaku, 19, $673(1970)$

4. Y. Nishikawa, "Keikou Shigai Kyushu Bunseki", p. 15, Kyouritsu Shuppan, Tokyo (1965).

(Received January 11, 1988) (Accepted April 4, 1988) 